\title{
KORELASI AKTIFITAS FISIK DAN KOMPOSISI TUBUH DENGAN DAYA TAHAN JANTUNG PARU
}

\author{
Titing Nurhayati ${ }^{1}$, Hanna Goenawan ${ }^{1,}$ Reni Farenia $^{1}$, Adjat Setiadjati Rasjad ${ }^{1,2}$, Ambrosius Purba ${ }^{1}$ \\ ${ }^{1}$ Departemen Anatomi, Fisiologi dan Biologi Sel Fakultas Kedokteran Universitas Padjadjaran, Bandung \\ ${ }^{2}$ Departemen Fisiologi Fakultas Kedokteran Universitas Islam Bandung
}

\begin{abstract}
Pencak silat refers to performance sport requiring good physical condition. This study objective was to investigate the correlation between the physical activities and the body composition (fat percentage) to the cardiopulmonary endurance in female and male player-categorized athletes of pencak silat at Pelatda PON XVII Jawa Barat. The subjects of the study consisted of 20 pelatda athletes. The athletes conducted test of cardiopulmonary endurance using Astrand's bench, daily intake was measured by food records $7 \times 24$ hours, physical activity was measured by activity records $7 \times 24$ hours, body composition was measured by skinfold calliper. The data was analyzed using Pearson's correlation test. The conclusion, there were a close positive correlation of the physical activity to the cardiopulmonary endurance of all subjects, there was also a close negative correlation of the body composition (fat percentage) to the cardiopulmonary endurance of male athletes, while a weak positive correlation of female athletes.
\end{abstract}

Keywords: physical activities, body composition, fat percentage, cardiopulmonary endurance, pencak silat athletes.

Korespondensi: Titing Nurhayati, E-mail: amrosdianto@gmail.com , Departemen Anatomi, Fisiologi, dan Biologi Sel, Fakultas Kedokteran Universitas Padjadjaran. Jalan Raya Jatinangor Km 21, Sumedang, Jawa Barat, Indonesia. 


\section{PENDAHULUAN}

Prestasi pesilat Indonesia di beberapa kejuaraan tingkat internasional, ASEAN, nasional semakin hari semakin menurun. Hal ini dapat dilihat dari data prestasi atlet Jawa Barat pada PON XVI, hanya terdapat 2 atlet yang mendapatkan medali emas dari 3 emas yang ditargetkan pada PON XVI (KONI JABAR, 2006).

Pelatda Jawa Barat melakukan persiapan dan pembinaan khusus dalam rangka meningkatkan prestasi atlet-atletnya, khususnya atlet pencak silat kategori tanding. Akan tetapi pembinaan tidak cukup melalui teknik-teknik bertanding namun juga perlu diperhatikan upaya untuk meningkatkan kebugaran jasmani, dengan meningkatkan daya tahan jantung paru.

Apabila dilihat dari frekuensi latihan atlet pelatda Jawa Barat cabang olahraga pencak silat yang dilakukan 1-2 kali seminggu, dan sisa waktu dalam satu minggu digunakan untuk latihan tehnik dan taktik setiap hari, hal inilah yang kemungkinan turut meningkatkan daya tahan jantung paru atlet pelatda Jawa Barat, atau dengan perkataan lain bahwa aktifitas fisik berupa latihan kondisi fisik, tehnik dan aktifitas fisik di luar latihan fisik berperan dalam mempengaruhi daya tahan jantung paru. Walaupun menurut Bompa ${ }^{1,2}$ latihan yang dapat meningkatkan daya tahan jantung paru dilakukan 2-3x seminggu dengan intensitas $75-85 \%$ dari denyut nadi maksimal dan dilakukan lebih dari 1 jam.

Selain daya tahan jantung paru, komposisi tubuh (persentase lemak) yang berperan dalam menentukan keberhasilan seorang atlet pencak silat pelatda Jawa Barat untuk meningkatkan prestasi maksimal, oleh karena komposisi tubuh yang tidak ideal akan menyebabkan kelincahan dan daya tahan atlet semakin menurun ${ }^{2}$. Komposisi tubuh (persentase lemak) dipengaruhi oleh asupan makanan seharihari dan tingkat aktivitas fisik ${ }^{3,4,2}$. Asupan kalori yang tidak sesuai dengan penggunaan kalori menyebabkan terjadinya ketidakseimbangan energi. Kelebihan energi ataupun kekurangan energi mengakibatkan menurunnya kebugaran jasmani, oleh karena asupan $\mathrm{O}_{2}$ ke paru dan perfusi $\mathrm{O}_{2}$ dari pembuluh darah perifer ke otot terganggu akibat adanya timbunan lemak $^{2,5}$. Berkaitan dengan paparan tersebut, kemungkinan terdapat hubungan antara daya tahan jantung paru dengan komposisi tubuh (persentase lemak). Adapun komposisi tubuh (persentase lemak) sangat tergantung dari asupan kalori dan penggunaan kalori.

Adapun yang dimaksud dengan aktifitas fisik atlet PELATDA JABAR adalah kegiatan latihan fisik selama 1-2 hari setiap minggu, latihan taktik dan tehnik selama 4 hari dan aktifitas lainnya selama latihan.

Pentingnya penelusuran keterkaitan antara daya tahan jantung paru dengan aktifitas fisik dan komposisi lemak tubuh dalam rangka menyusun program latihan dan asupan kalori yang sesuai agar mendukung pencapaian prestasi maksimal pada atlet pelatda Jawa Barat PON XVII di Kalimantan Timur.

\section{METODE}

Subjek dalam penelitian ini ialah atlet Subjek penelitian dipilih berdasarkan total sampling yang terdiri dari 20 orang (10 orang putra dan 10 orang putri). Subjek telah menandatangani lembar persetujuan pemeriksaan (informed consent).

\section{Subjek Penelitian}

Subjek pada penelitian ini adalah atlet pencak silat Pelatda PON XVII Jawa Barat yang terdiri dari 10 orang putra dan 10 orang putri. Subjek penelitian diberikan informed consent sebelum pelaksanaan penelitian. Penelitian ini sudah mendapakan ijin dari Komite Etik Fakultas Kedokteran Universitas Padjadjaran.

Penelitian.

Metode penelitian ini adalah survei analitik korelasional, dengan desain sebagai berikut:

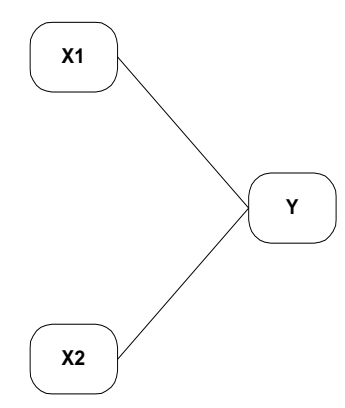

Keterangan:

X1 : Aktifitas fisik

$\mathbf{X 2}$ : Komposisi tubuh (persentase lemak)

Y : Daya tahan jantung paru 


\section{Pemeriksaan Kebugaran Subjek}

Daya tahan jantung paru pada penelitian ini indikatornya adalah $\left(\mathrm{VO}_{2}\right.$ maks) yang dinilai dengan melakukan tes naik turun bangku Astrand. Asupan kalori harian diukur dengan metode catatan pangan (food records) 7x24 jam. Aktifitas fisik diukur dengan metode catatan aktifitas (activity records) dalam 7x24 jam. Komposisi tubuh (persentase lemak) diukur dengan alat skinfold calliper.

\section{Analisis Data}

Sebaran nilai data pada setiap kelompok dinilai uji normalitas Kolmogorov-Smirnov $(p>0,05)$ dan uji homogenitas varians levene test ( $>>0,05)$. Kekuatan hubungan antar variabel pada setiap kelompok dianalisis dengan menggunakan uji korelasi Pearson.

\section{HASIL}

Hasil penelitian memperlihatkan usia subyek penelitian berkisar 23 tahun pada putra dan 20 tahun pada putri dengan presentase lemak tubuh $11,98 \%$ pada putra dan lebih tinggi pda putri yaitu $17,20 \%$. Sedangkan aktifitas fisik berkisar $1732 \mathrm{kkal}$ pada putra dan $1272 \mathrm{kkal}$ pada putri. Daya tahan jantung paru berkisar 45,50 $\mathrm{ml} / \mathrm{kg} \mathrm{BB} /$ menit pada putra dan $28,90 \mathrm{ml} / \mathrm{kg}$ $\mathrm{BB} /$ menit pada putri.

Hasil pengukuran daya tahan jantung paru $\left(\mathrm{VO}_{2}\right.$ maks) dengan aktifitas fisik atlet pencak silat putra dan putri kategori tanding Pelatda Jawa Barat dengan menggunakan uji Pearson $(p \leq 0,05)$ hasilnya terdapat korelasi positif erat $(\mathrm{r}=0,896)$. Begitu pula pada atlet putera bahwa terdapat korelasi positif erat antara aktifitas fisik dan daya tahan jantung paru $(r=0,854)$. Hal yang sama juga terdapat pada atlet putri dimana terdapat korelasi positif sangat erat antara aktifitas fisik dan daya tahan jantung paru $(\mathrm{r}=0,953)$. Dapat dilihat pada Tabel 2.

Tabel 1. Karakteristik Fisik Fisiologis Atlet Pencak Silat Putra dan Putri Kategori Tanding Pelatda Jawa Barat yang Dipersiapkan untuk PON XVII di Kalimantan Timur

\begin{tabular}{|c|c|c|c|c|c|c|}
\hline \multirow{2}{*}{ Variabel } & \multicolumn{6}{|c|}{ Rata-rata dan Simpangan Baku } \\
\hline & \multicolumn{3}{|c|}{ Putra } & \multicolumn{3}{|c|}{ Putri } \\
\hline 1. Umur ( th ) & 23,40 & \pm & 3,24 & 20,60 & \pm & 3,86 \\
\hline 2. Berat ( kg ) & 68,20 & \pm & 12,98 & 59,06 & \pm & 8,89 \\
\hline 3. Tinggi badan $(\mathrm{cm})$ & 169,75 & \pm & 7,76 & 163,20 & \pm & 5,88 \\
\hline 4. Nadi ( kali/menit ) & 65,60 & \pm & 8,93 & 73,20 & \pm & 11,16 \\
\hline 5. Respirasi ( kali/menit ) & 19,40 & \pm & 0,97 & 19,40 & \pm & 0,97 \\
\hline 6. Sistole ( $\mathrm{mmHg}$ ) & 118,00 & \pm & 12,06 & 105,00 & \pm & 7,07 \\
\hline 7. Diastole ( $\mathrm{mmHg}$ ) & 76,50 & \pm & 9,44 & 71,50 & \pm & 3,37 \\
\hline 8. IMT ( $\left.\mathrm{BB} / \mathrm{kg} \mathrm{m}^{2}\right)$ & 23,48 & \pm & 2,88 & 22,08 & \pm & 2,31 \\
\hline 9. \% Lemak & 11,98 & \pm & 5,20 & 17,20 & \pm & 4,77 \\
\hline 10. $\mathrm{VO}_{2}$ maks & 45,50 & \pm & 6,35 & 38,90 & \pm & 3,51 \\
\hline 11. Aktifitas Fisik (kkal) & 1732,45 & \pm & 295,78 & 1272,71 & \pm & 323,07 \\
\hline 12. TEE (kkal) & 3706,18 & \pm & 379,25 & 2803,25 & \pm & 485,56 \\
\hline 13. Asupan Kalori (kkal) & 3985,61 & \pm & 465,05 & 3129,75 & \pm & 582,96 \\
\hline
\end{tabular}


Tabel 2. Korelasi Antara Aktifitas Fisik dan Komposisi Tubuh dengan Daya Tahan Jantung Paru $\left(\mathrm{VO}_{2}\right.$ maks) pada Atlet Pencak Silat Putra dan Putri Kategori Tanding Pelatda PON XVII Jawa Barat

\begin{tabular}{ccccc}
\hline Variabel & Atlet & $\mathbf{r}$ & Kategori & P Value \\
\hline $\begin{array}{c}\text { Aktifitas } \\
\text { Fisik dengan } \\
\mathrm{VO}_{2} \text { maks }\end{array}$ & Putra & 0,854 & $\begin{array}{c}\text { Korelasi } \\
\text { positif erat } \\
\text { Korelasi }\end{array}$ & $\mathrm{p}<0.005$ \\
Putri & 0,953 & $\begin{array}{c}\text { positif sangat } \\
\text { erat } \\
\text { Korelasi }\end{array}$ & $\mathrm{p}=0.0053$ \\
$\begin{array}{c}\text { \% Lemak } \\
\text { dengan }\end{array}$ & Putra & $-0,630$ & $\begin{array}{c}\text { negatif cukup } \\
\text { erat }\end{array}$ & \\
$\mathrm{VO}_{2}$ maks & Putri & 0,355 & $\begin{array}{c}\text { Korelasi } \\
\text { positif lemah }\end{array}$ & $\mathrm{p}=0.186$ \\
\hline
\end{tabular}

\section{PEMBAHASAN}

Dari hasil tersebut dapat dijelaskan bahwa dengan frekuensi latihan atlet Pelatda Jawa Barat cabang olahraga pencak silat kategori tanding yang walaupun hanya dilakukan 1-2 kali seminggu, dan sisa waktu dalam satu minggu digunakan untuk latihan tehnik dan taktik setiap hari, hal inilah yang kemungkinan turut meningkatkan daya tahan jantung paru atlet Pelatda Jawa Barat, atau dengan perkataan lain bahwa aktifitas fisik berupa latihan kondisi fisik, tehnik dan aktifitas fisik di luar latihan fisik berperan dalam mempengaruhi daya tahan jantung paru.

Daya tahan jantung paru sangat tergantung dari kapasitas paru, kemampuan pompa jantung, kemampuan hemoglobin untuk mengikat $\mathrm{O}_{2}$, dan kecepatan perfusi $\mathrm{O}_{2}$ dari pembuluh darah perifer ke dalam otot.

Latihan fisik yang terukur dan terprogram dengan baik termasuk frekuensi latihan 3-5 kali dalam seminggu akan menyebabkan kemampuan inspirasi dan kemampuan fungsi paru maksimal karena kemampuan mengembang paru rendah disertai kemampuan otot-otot pernafasan untuk mengatasi resistensi udara yang maksimal. Dengan latihan yang cukup untuk meningkatkan daya tahan jantung paru $\left(\mathrm{VO}_{2}\right.$ maks) sebagaimana disebutkan diatas akan menyebabkan meningkatnya fungsi paru ${ }^{2}$.

Selain faktor yang tersebut di atas, untuk meningkatkan daya tahan jantung paru terdapat faktor pertukaran gas dari alveolus ke pembuluh kapiler paru dan luasnya permukaan alveoli tempat terjadinya proses difusi $\mathrm{O}_{2} \mathrm{ke}$ pembuluh darah kapiler paru. Latihan yang tepat mengakibatkan maksimalnya pertambahan luas permukaan alveolus tempat terjadinya proses difusi $\mathrm{O}_{2}$ ke pembuluh kapiler paru, serta jumlah mikrosirkulasi yang aktif sekitar alveolus.

Selain faktor pertukaran gas dan luasnya permukaan alveoli tempat terjanya difusi $\mathrm{O}_{2}$, terdapat pula kemampuan inspirasi otot paru maksimal yang akan menyebabkan peningkatan kapasitas difusi dari alveoli ke dalam darah yang lebih maksimal pula, sehingga konsentrasi $\mathrm{O}_{2}$ dalam darah bertambah secara maksimal pula. Dari hasil penelitian Douhamel ${ }^{6}$, pada orang terlatih kemampuan volume i nspirasi meningkat sebanyak 30\% dibandingkan sebelum latihan. Hal ini menunjukkan dengan latihan yang terukur dan terprogram dengan baik akan meningkatkan volume udara di alveoli sehingga jumlah $\mathrm{O}_{2}$ yang berdifusi dari alveoli ke kapiler perialveolar meningkat ${ }^{7,8}$.

Respon adaptif awal dari latihan aerobik adalah peningkatan volume darah pada organorgan yang turut aktif dalam aktifitas fisik. Darah mengandung eritrosit yang hampir seluruhnya terisi oleh hemoglbin $(\mathrm{Hb})$. Kandungan heme dalam $\mathrm{Hb}$ mempunyai kemampuan mengikat $\mathrm{O}_{2}$ yang sangat dipengaruhi enzim 2,3 difosfogliserol (DPG) dan kemampuan mengikat $\mathrm{CO}_{2}$ dengan bantuan enzim karbonik anhidrase. Peningkatan kadar enzim akibat latihan sangat berpengaruh dengan peningkatan $\mathrm{O}_{2}$ oleh $\mathrm{Hb}$ dan $\mathrm{CO}_{2}$ oleh $\mathrm{Hb}$ di paru-paru. Demikian pula halnya difusi $\mathrm{O}_{2}$ di jaringan akan lebih mudah akibat peran enzim 2,3 difosfogliseol (DPG) di dalam otot serta pelepasan $\mathrm{CO}_{2}$ dari jarinngan ke kapiler otot menjadi lebih baik. Semua ini sangat tergantung dari kadarkadar enzim yang disebutkan tadi dan kadar enzim tersebut dipengaruhi oleh latihan yang terukur dan terprogram dengan baik ${ }^{9}$.

Dari uraian di atas untuk meningkatkan $\mathrm{VO}_{2}$ maks yang dipengaruhi oleh fungsi paru dan $\mathrm{Hb}$, terdapat pula pengaruh dari fungsi jantung. Frekuensi latihan yang maksimal dalam aerobik akan meningkatkan efisiensi kerja jantung melalui dua mekanisme, yaitu jumlah darah yang dipompa setiap denyut lebih besar dan frekuensi denyutan berkurang. Efisiensi kerja jantung meningkat akibat peningkatan kontraktilitas otot jantung, dan peningkatan interaksi elemen-elemen kontraktilitas sel otot jantung karena peningkatan availibilitas kalsium $\left(\mathrm{Ca}^{2+}\right)$ ekstraselular dan aktifitas enzim ATPase. Peningkatan availibilitas kalium $\left(\mathrm{Ca}^{2+}\right)$ ini terjadi melalui dua mekanisme yaitu pertama peningkatan afinitas mitokondria terhadap ion kalsium $\left(\mathrm{Ca}^{2+}\right)$ dan peningkatan influks $\mathrm{Ca}^{2+}$ dan mekanisme kedua yaitu peningkatan jumlah kalsium $\left(\mathrm{Ca}^{2+}\right)$ mitokondria yang mempengaruhi mekanisme fosforilasi oksidasi. Mekanisme fosforilasi oksidasi 
menyebabkan peningkatan ATP akibatnya konsumsi $\mathrm{O}_{2}$ meningkat ${ }^{10}$.

Pengaruh latihan yang teratur dengan frekuensi 3-5 kali dalam seminggu, intensitas 75$85 \%$ dari denyut nadi maksimal, selama 60 menit selain meningkatkan proses metabolisme di atas, dapat pula menyebabkan penebalan otot jantung yang diakibatkan oleh latihan tersebut karena tonus simpatis menurun dan tonus parasimpatis meningkat yang mempengaruhi frekuensi jantung. Selain perubahan yang disebut di atas terdapat pula peningkatan isi sekuncup yang akan menyebabkan peningkatan curah jantung. Peningkatan isi sekuncup dan penurunan denyut nadi menyebabkan peningkatan curah jantung ${ }^{11}$. Pengaruh latihan aerobik menurut Fleg, Schulman dan Connor akan menyebabkan volume akhir diastolik lebih besar sehingga pengisian darah ke pembuluh darah koroner relatif besar dan hal ini turut mempengaruhi daya tahan jantung paru untuk memompa darah.

Faktor lain yang menentukan daya tahan jantung paru adalah kemampuan otot untukmengkonsumsi oksigen secara maksimal. Dengan latihan akan menyebabkan densitas kapiler dan luas permukaan difusi $\mathrm{O}_{2}$ di dalam otot meningkat. Selain itu akan menyebabkan difusi $\mathrm{O}_{2}$ dari kapiler ke otot lebih mudah, difusi $\mathrm{CO}_{2}$ dari otot ke kapiler serta metabolisme aerobik pembentukan energi di dalam otot menjadi lebih baik $^{13}$. Semua proses ini dapat terjadi oleh karena latihan aerobik meningkatkan enzim-enzim oksidasi di dalam otot. Apabila latihan kurang terukur dan terprogram dengan baik akan menyebabkan menurunnya jumlah, ukuran, serta luas permukaan mitokondria otot skelet dan menurunnya konsentrasi enzim oksidasi yang berperan dalam siklus Krebs dan siklus beta oksidasi untuk pemecahan asam lemak bebas ${ }^{6}$.

Dari uraian di atas dapat menunjukkan bahwa aktifitas fisik yang dilakukan relatif cukup tinggi kemungkinan akan meningkatkan daya tahan jantung paru.

Hasil pengukuran daya tahan jantung paru dengan komposisi tubuh (\% lemak) pada atlet pencak silat putra dan putri kategori tanding Pelatda Jawa Barat dengan menggunakan uji Pearson $(p \leq 0,05)$ bahwa terdapat korelasi negatif cukup erat antara komposisi lemak tubuh dan daya tahan jantung paru pada atlet pencak silat putra dan putri $(\mathrm{r}=-0,481)$. Begitu pula pada atlet pencak silat kategori tanding putra bahwa terdapat korelasi negatif cukup erat antara komposisi lemak tubuh dan daya tahan jantung paru dengan $r=-0,630$. Dan pada atlet pencak silat putri kategori tanding terdapat korelasi positif lemah antara komposisi lemak tubuh dan daya tahan jantung paru $(\mathrm{r}=0,355)$.

Pada atlet putra bahwa terdapat korelasi negatif antara komposisi lemak tubuh dan daya tahan jantung paru dengan kata lain makin tinggi daya tahan jantung paru maka makin rendah komposisi lemak tubuh. Hal yang sama terjadi pada atlet putri bahwa terjadi korelasi yang lemah antara daya tahan jantung paru dengan komposisi lemak tubuh dan begitu pula sebaliknya. Hal ini menunjukkan bahwa faktor asupan makanan yang lebih banyak mengandung karbohidrat pada atlet putra dan putri pencak silat kategori tanding, kemungkinan yang menyebabkan terjadinya persentase lemak tubuh yang berlebih. Kelebihan energi ataupun kekurangan energi mengakibatkan menurunnya kebugaran jasmani, oleh karena asupan $\mathrm{O}_{2}$ ke paru dan perfusi $\mathrm{O}_{2}$ dari pembuluh darah perifer ke otot terganggu akibat adanya timbunan lemak. $\mathrm{H}$ al ini sejalan dengan hasil uji $\mathrm{t}$ yang bermakna dengan perbedaan antara asupan kalori dan penggunaan kalori pada atlet pencak silat putra asupan kalori lebih besar dari penggunaan kalori $(3985,61 \mathrm{Kkal}$ vs 3706,18 Kkal). Begitu pula pada atlet putri hasil uji $t$ bermakna dengan asupan kalori lebih besar dari penggunaan kalori $(3129,75 \mathrm{Kkal}$ vs 2803,25 Kkal). Hal ini dapat disimpulkan bahwa faktor yang berperan untuk meningkatkan komposisi lemak tubuh pada atlet putra dan putri pencak silat kategori tanding adalah asupan kalori yang lebih dari pada penggunaan kalori.

Komposisi lemak tubuh dipengaruhi oleh asupan makanan sehari-hari dan tingkat aktivitas fisik $^{3,4,2}$. Asupan makanan yang lebih banyak mengandung karbohidrat dalam bentuk monosakarida, disertai aktivitas fisik yang terbatas menyebabkan glukosa yang berlebih akan disimpan dalam bentuk lemak dalam tubuh. Terbatasnya aktivitas fisik juga akan mengurangi jumlah enzim lipoprotein lipase (LPL) yang berguna untuk degradasi lipoprotein, sehingga banyak lemak yang disimpan dalam bentuk trigliserid dalam tubuh ${ }^{5,2}$. Selain itu, metabolisme basal yang rendah menentukan $2 / 3$ dari jumlah total pengeluaran energi, sehingga dengan metabolisme basal yang rendah, resiko terjadinya persentase lemak tubuh berlebih menjadi lebih tinggi ${ }^{12}$. Kurangnya aktifitas fisik serta asupan makanan yang lebih banyak mengandung karbohidrat kemungkinan menyebabkan terjadinya persentase lemak tubuh yang berlebih. Kelebihan energi ataupun kekurangan energi mengakibatkan menurunnya kebugaran jasmani, oleh karena asupan $\mathrm{O}_{2}$ ke paru dan perfusi $\mathrm{O}_{2}$ dari 
pembuluh darah perifer ke otot terganggu akibat adanya timbunan lemak ${ }^{2,5}$. Asupan gizi pada atlet Pelatda Jawa Barat tidak terkontrol, pemberian uang kompensasi bulanan untuk meningkatkan asupan gizi akan meningkatkan asupan gizi.

Hal ini sesuai dengan pendapat Foss \& Keteyian $^{2}$ yang menyatakan bahwa makanan yang banyak mengandung monosakarida (glukosa, fruktosa) akan diabsorbsi oleh usus halus dan masuk ke dalam hati untuk diubah menjadi glukosa yang kemudian diedarkan ke seluruh tubuh atau disimpan dalam bentuk glikogen di hati dan otot. Bila hati dan otot telah terisi penuh dengan glikogen yang dihasilkan dari metabolisme monosakarida tersebut, maka glukosa akan diubah oleh sel adiposa menjadi lemak sebagai energi yang tersimpan dalam tubuh.

Dari uraian di atas dapat menunjukkan bahwa komposisi lemak tubuh yang cukup tinggi kemungkinan akan menurunkan daya tahan jantung paru.

\section{KESIMPULAN}

Pada penelitian ini dapat ditarik kesimpulan bahwa terdapat hubungan positif erat antara aktifitas fisik dengan daya tahan jantung paru $\left(\mathrm{VO}_{2}\right.$ maks $)$ pada atlet pencak silat putra kategori tanding, artinya semakin tinggi aktifitas fisik maka semakin baik daya tahan jantung paru. Disamping itu, terdapat hubungan positif sangat erat antara aktifitas fisik dengan daya tahan jantung paru $\left(\mathrm{VO}_{2}\right.$ maks $)$ pada atlet pencak silat putri kategori tanding, artinya semakin tinggi aktifitas fisik maka semakin baik daya tahan jantung paru. Sebaliknya terdapat hubungan negatif cukup erat antara komposisi tubuh (persentase lemak) dengan daya tahan jantung paru $\left(\mathrm{VO}_{2}\right.$ maks $)$ pada atlet pencak silat putra kategori tanding, artinya semakin rendah komposisi lemak tubuh maka semakin baik daya tahan jantung paru dan terdapat hubungan positif lemah antara komposisi tubuh (persentase lemak) dengan daya tahan jantung paru $\left(\mathrm{VO}_{2}\right.$ maks) pada atlet pencak silat putri kategori tanding, artinya pada komposisi lemak tubuh yang rendah tidak selalu daya tahan jantung paru baik.

\section{DAFTAR PUSTAKA}

1. Bompa TO. Theory and Methodology of Training. Kendal/Hunt Publishing Company. 1983.

2. Foss ML, Keteyian SJ. Fox's Physiological Basis for Exercise and Sport. Dubuque, lowa: McGraw Hill Book Company. 1998.
3. Gibson, SR. Principes of Nutrition Assesment New Yrk: Oxford University Press. 1990.

4. Bouchard C, Shephard RJ, Stephens T, Sutton JR, McPherson BD. Exercise, Fitness, and Health: A Consensus of Current Knowledge. USA: Human Kinetik Publishers, Inc. 1990.

5. Astrand P, et al. Textbook of Work Physiology: Physiological Bases of Exercise $4^{\text {th }}$ Edition. Human Kinetics Publishers. New York. 2003.

6. Duhamel TA, Green HJ, Sanford SD, Perco JG, \& Ouyang J. Effects of progressive exercise and hypoxia on human muscle sarcoplasmic reticulum function. $J$ of Appl Physiol. 2004;97(1):188-196.

7. Harman CA. et al. Effects of respiratory muscle work on cardiac output and its distribution during maximal exercise. $J$ of Appl Physiol. 1998; 85(2): 609-618.

8. Grassi B. et al. Muscle Oxygenation and Pulmonary gas excange kitecs during cycling exercise on transitions in human, $J$ of Appl Physiol. 2003; 95(1): 149-158.

9. Henderson KK, McCanse W, Urano T, Kuwahira I, Clancy R, \& Gonzalez NC. Acute vs. Chronic effects of elevated hemoglobine $\mathrm{O}_{2}$ affinity on $\mathrm{O}_{2}$ transport in maximal exercise. $J$ of Appl Physiol. 2000;89(1):265275.

10. Hunter SK, et al. Human skeletal sarcoplasmic reticulum $\mathrm{Ca}^{+}$uptake and muscle function with aging and strength training. J of Appl Physiol. 1999;86(6):18581865.

11. Gurd BJ, Scheuermann B, Paterson DH, \& Kowalchuk JM. Prior heavy-intensity exercise speeds $\mathrm{VO}_{2}$ kinetics during moderateintensity exercise in young adults. $J$ of Appl Physiol. 2005;98(4): 1371-1378.

12. Hill JO, Donahoo WT. Environmenal Contribution to Obesity. Melalui http://www.endotext.org/obesity/obesity7/obe sity 7.htm. 2002.

13. Kemp G. Kinetics of muscle oxygen use, oxygen content, and blood flow during exercise. J of Appl Physiol. 2005.99(6):24632469 